\title{
Preface
}

\section{Journal of Facade Design and Engineering}

We are delighted to announce the launch of the Journal of Facade Design and Engineering. It is the result of an ongoing discussion with colleagues from our discipline about the need for a scientific platform that focusses on the building envelope.

Since we founded the Façade Research Group at the TU Deft in 2005, we observed a growing demand for façade design and engineering in the building field. One reason obviously is the importance of the facade related to the energy consumption of buildings as well as the user comfort. This development is also reflected in the scientific field; with many questions yet to be answered. They concern technologies, methods and tools to reach the above mentioned energy savings of buildings. We need to investigate constructional, functional and formal developments of the building envelope and we need more fundamental and in-depth knowledge about façade building materials and structural aspects.

This means Façade Design and Engineering is a multidisciplinary field that touches many other scientific disciplines such as Climate Design, Building Physics, Structural Design, Architectural Design, Process Management, Product Development and many more. On top of that, we believe that the dissemination of science into practice and industrial innovations must be one of the main targets of the journal.

When the European Façade Network was founded in 2009 (http://facades.ning.com), an international community was established that allowed us to start creating a new scientific platform: Facade Design and Engineering is a peer reviewed, open access journal, funded by The Netherlands Organisation for Scientific Research NWO (www.nwo.nl). We see 'open access' as the future publishing model. But it certainly requires new financial models which we will have to explore in the coming years. However, primarily it is a great opportunity to attract a broad, open and lively audience and author community.

The first issue is an important step. We received a lot of interesting paper contribution by different colleagues and the following issues are already planned. The final goal is to publish four 4 issues per year. While proceeding, we now face the challenging task to shape the scope of the journal in detail (which is currently rather broad) and we need your valuable contribution to it. The published content is one outcome of this activity; the other is the scientific discussion around our interesting discipline.

May JFDE become a valuable resource for professionals and academics involved in the design and engineering of the building envelope. We are looking forward to many interesting contributions and discussions!

Ulrich Knaack, Tillmann Klein

ISSN 2213-302X/13/\$27.50 (C) 2013 - IOS Press and the authors. All rights reserved

This article is published online with Open Access and distributed under the terms of the Creative Commons Attribution Non-Commercial License. 